\title{
Museus, ciência e educação: novos desafios
}

VALENTE, M. E., CAZELLI, S. e ALVES, F.: Museus, ciência e educação: novos desafios. História, Ciências, Saúde - Manguinhos, vol. 12 (suplemento), p. 183-203, 2005.

Este artigo discute a conformação do papel social dos museus de ciência pelo fazer científico e tecnológico, pelas demandas da sociedade e pelas questões educacionais, sobretudo na negociação com seus públicos. Analisam-se a trajetória de consolidação dos museus de ciência no Brasil e as modificações dessas instituições impostas pela sociedade atual. Discute-se como a comunicação tornou-se o centro da discussão sobre cultura museal, especialmente por redimensionar $\mathrm{o}$ aspecto educacional segundo a concepção de práticas sociais, consideradas recursos fundamentais. Examinase, também, a incorporação das idéias de 'risco' e 'incerteza' produzidas pela ciência a essa nova forma de pensar os museus, na qual público e processos comunicacionais são valorizados.

PALAVRAS-CHAVE: museus de ciência; educação/comunicação; interatividade; sociedade de risco, cultura científica.

VALENTE, M. E., CAZELLI, S. e ALVES, F.: Museums, science, and education: new challenges.

História, Ciências, Saúde-Manguinhos, vol. 12 (supplement), p. 183-203, 2005.

The article discusses how the social role of science museums is shaped by scientific and technological endeavor, society's demands, and educational issues, above all in negotiations with a museum's audiences. The text also analyzes the trajectory taken by Brazil's science museums in their process of consolidation and the changes current society has imposed on these institutes. Communication has become the center of the discussion on museum culture, particularly in that it adjusts the educational aspect according to the conception of social practices, which are deemed fundamental resources. Lastly, the article examines the incorporation of the ideas of 'risk' and 'uncertainty', produced by science, into this new way of thinking about museums, which values the public and communication processes.

KEYWORDS: science museums, education/ communication, interactivity, risk society, scientific culture. 


\section{Introdução}

A temática voltada para a relação público-museu vem ganhando A amplo espaço em fóruns de discussão e publicações das áreas das ciências sociais, bem como tem se diversificado em interesses que abarcam inúmeros aspectos, desde os diversos tipos de museus até os diferentes públicos, estes igualmente desdobrados segundo gênero, idade, formação e procedência, entre outros. Os temas também relacionam-se a várias problemáticas de caráter científico ou social, envolvendo disciplinas de campos distintos. No leque dessas possibilidades de estudo, os museus de ciência se situam em um setor particular, vinculado às questões da divulgação científica e suas implicações com o entendimento público da ciência.

Os museus de ciência acompanham a sociedade por mais de três séculos e, ultimamente, vêm sofrendo mudanças marcantes e profundas na sua concepção de acessibilidade pública: anteriormente meros armazéns de objetos, são considerados hoje lugares de aprendizagem ativa. Isso porque os museus atuais devem olhar igualmente para as suas coleções e para o seu público. Influenciam outras categorias de museus e organizam-se, ao longo do tempo, de forma quase constante, mantendo presente sua ligação com as questões de cunho educacional (Valente, 1995).

O presente artigo pretende refletir sobre como o fazer científico e tecnológico, as demandas da sociedade e as questões educacionais vêm conformando o papel social dos museus de ciência, sobretudo na negociação com seus públicos. Para a absorção de novas idéias e tendências por parte dessas instituições, o replanejamento das formas de trabalho ganha destaque. Tal abordagem possibilita compreender como, atualmente, a comunicação tornou-se o centro da discussão da cultura do museu, especialmente por redimensionar o aspecto educacional das práticas sociais, consideradas recursos fundamentais para que os museus possam acompanhar as redefinições de tempo e espaço social operadas pelas rápidas mudanças do mundo contemporâneo.

\section{Museus de ciência no Brasil: o caminho percorrido}

No Brasil, o movimento de criação dos museus de ciência não tem sido o foco de investigações de historiadores da ciência, a despeito de estudos evidenciarem a rica contribuição dos museus para a consolidação das ciências naturais no país. Os primeiros museus brasileiros possuíam temática científica, como observa Lopes (1996), uma decorrência da exuberância da natureza brasileira. O Museu Nacional do Rio de Janeiro, criado em 1818 e organizado durante um século, foi a primeira instituição brasileira dedicada primordialmente à história natural. O Museu Paraense Emílio Goeldi, em 
Belém, no Pará, criado em 1866, e o Museu Paulista, conhecido anteriormente como Museu do Ipiranga, criado em São Paulo, em 1894, são exemplos de instituições dedicadas às ciências naturais e consolidadas a partir da segunda metade do século XIX, principalmente a partir das contribuições dos especialistas estrangeiros (Lopes, 1997). Mesmo uma abordagem panorâmica sobre a formação dos museus de ciência no Brasil permite observar como a trajetória dessas instituições foi marcada por compromissos estabelecidos a partir de diferentes perspectivas de educação e difusão da ciência, consonantes com os momentos em que surgiram esses museus.

A criação do Museu Nacional, por exemplo, integrou o programa de modernização do país provocado pela vinda da família real portuguesa. O museu era símbolo de urbanismo, civilização e progresso. Sua conformação original teve por referência os museus europeus, em especial o Muséum National d'Histoire Naturelle de Paris. Caracterizava-se por ser uma instituição aberta ao público, e desde sua inauguração, embora de forma não-sistemática, ofereceu cursos e palestras populares. Entretanto, instalado no século XIX em um país escravocrata, seu público restringia-se aos letrados. No tempo em que a separação das disciplinas do conhecimento estava por se firmar, a concepção de ciência, nesse museu, ainda era associada a pesquisa, arte e indústria, sem que houvesse contradição nessa relação. Dentre suas funções incluíam-se a profissionalização de naturalistas e a promoção de expedições científicas, o que lhe conferia o atributo de construtor da identidade nacional.

Na Europa desse período, a formação dos Estados nacionais e o desenvolvimento científico e tecnológico garantiam a conquista de partes territoriais do globo e asseguravam o domínio das fontes de energia disponíveis, impondo a hegemonia européia do saber, do poder e da riqueza. As grandes exposições internacionais da indústria são emblemáticas dessa época, visto que expressavam a capacidade técnica com que a sociedade industrial burguesa manifestava seu orgulho. A 1aㅡ Exposição Internacional, inaugurada em maio de 1851, em Londres, foi montada em um grande palácio de cristal, símbolo da grandeza que anunciava uma nova forma de cooperação entre ciência, técnica e indústria. As máquinas expostas eram ícones dos tempos modernos, e ciência e técnica conjugavamse para promover o progresso, o ideal que fazia caminhar a sociedade (Neves, 2001). Cabe destacar que desde a 3a Exposição, realizada na capital inglesa em 1862, o Brasil participou desses eventos.

Perseguindo o ideal de melhor implementar a vida social, a organização de tais exposições destacou progressivamente a temática educacional como instrumento impulsionador de transformação, a ocupar um espaço privilegiado ao lado da produção industrial e artística e da demonstração de novidades tecnológicas (Kuhlmann 
Júnior, 2001). A incorporação decorreu, entre outros aspectos, do fato de a educação ser então considerada um elemento estruturador da sociedade, não mais se restringindo apenas ao sistema de ensino. A dimensão educativa das exposições delineava uma 'pedagogia do progresso', cujo intuito era efetuar uma educação normativa para os mais diversos aspectos da vida social, exemplificada pela organização de "congressos e demonstrações públicas de técnicas de ensino atraindo, inclusive, grupos de visitantes, organizados pelos seus países de origem" (Heizer, 2002, p. 33).

Devido aos novos processos de trabalho desenvolvidos no século XX e advindos do desenvolvimento industrial e urbano, a sociedade via-se forçada, mais do que nunca, a acentuar seu processo de modernização, devendo para tanto tornar a educação um direito social de todos e responsável pela adaptação imperativa do homem às recentes demandas da sociedade. Conforme mencionado anteriormente, a passagem do século XIX para o XX foi envolvida por uma perspectiva otimista acerca do progresso da ciência e da tecnologia, de tal forma que acreditava-se que todos os povos do globo terrestre seriam finalmente atraídos para o campo da civilização (Cazelli, Franco, 2001). A ciência constituiu-se, então, em um mito que resolveria todos os problemas, além de ser considerada o melhor instrumento para promover uma sociedade civilizada. Uma nova era parecia predizer a evolução da natureza por meio de leis fundamentais e sob tal premissa a verdade científica seria definitivamente obtida.

No transcorrer das três primeiras décadas do século $X X$, os pontos de vista educacional e científico tiveram diferentes impactos nos museus, levando-os a uma reconfiguração. Do lado científico, a especialização de áreas do conhecimento provocou o surgimento de novos espaços de pesquisa, deslocando essa função dos museus para outros lugares. No que se refere ao aspecto educacional, acirrou-se seu papel pedagógico de cooperação com o ensino formal, instalando-se na instituição a característica da escolarização:

“... pela escolarização, queremos dizer que os museus abandonam seus objetivos de serem centros de comunicação e cultura para reduzir seu papel de complemento da formação promovida na escola conformando-se com os métodos de educação escolar tradicional" (Lopes, 1992, p. 263).

Foi na segunda metade do século XX que a relação entre ciência e técnica e seus então impensados avanços tornaram-se uma questão social, em particular depois da Segunda Guerra Mundial, quando se convivia com modelos econômicos baseados nas noções de desenvolvimento e progresso e com a introdução da energia nuclear controlada, que se mostrava como uma solução para os problemas energéticos. As esperanças depositadas nessa modalidade de energia 
durariam somente até se esclarecerem suas limitações. Ciência e cientistas tiveram suas imagens gradualmente estabelecidas na sociedade: ciência institucionalizada e cientistas profissionais. O lançamento do Sputnik, em 1957, foi o coroamento do progresso científico soviético e teve enorme impacto social, ao explicitar a distância entre a sociedade, o entendimento do papel da própria ciência e a educação. No cenário americano o impacto refletiu-se nos projetos curriculares, que alteraram os programas das disciplinas científicas. Surgem, por exemplo, o School Mathematics Study Group (SMSG) e o Biological Science Curriculum Study (BSCS), resultado do empenho do Comitê de Educação do American Institute of Biological Sciences (Krasilchick, 1987, p. 8).

No Brasil, também em meados da década de 1950, o Instituto Brasileiro de Educação, Ciência e Cultura (IBECC), criado por sugestão da Unesco, inicia suas atividades, marcando a inovação do ensino de ciências e o fortalecimento do ensino experimental. O órgão voltava-se para a montagem de kits portáteis e aparatos de baixo custo, que tinham como objetivo estimular o interesse dos jovens pela ciência. O IBECC realizou igualmente diversas ações com o propósito de promover uma ruptura nos padrões até então utilizados na educação em ciências, mas suas iniciativas tiveram pouca ressonância na realidade escolar, por encontrarem-se ainda distantes do trabalho docente.

As transformações políticas e sociais ocorridas na década de 1960 proporcionaram modificações na estrutura curricular do ensino de ciências. "Os grandes projetos passaram a incorporar mais um objetivo - permitir a vivência do método científico como necessário à formação do cidadão, não se restringindo mais apenas à preparação do futuro cientista" (idem, ibidem, p. 9). Deslocava-se, portanto, o referencial. A proposta era ir além das demonstrações experimentais conduzidas por professores, incorporando experiências realizadas pelos alunos. As tradicionais disciplinas científicas - matemática, física, química e biologia - passaram a exigir maior variedade de materiais didáticos e aparelhagem de laboratórios, a fim de garantir um ensino apoiado na vivência do método usado pelos cientistas para a produção de conhecimento. Enfatizaram-se os objetivos educacionais advindos dos estudos psicológicos do comportamentalismo americano, bem como a adoção de procedimentos científicos de avaliação.

A preocupação com a melhoria tanto do ensino quanto da preparação dos professores de ciências levou à a criação de um locus privilegiado de discussão dessas questões: os centros de ciência. Assim, em 1965, inicia-se a série dos CECIs: Centro de Ensino de Ciências do Nordeste (CECINE), Centro de Ciências da Bahia (CECIBA), Centro de Ciências de Minas Gerais (CECIMIG), Centro de Ciências da Guanabara (CECIGUA), Centro de Ciências de 
São Paulo (CECISP) e Centro de Ciências do Rio Grande do Sul (CECIRS). Inicialmente financiados pelo Ministério da Educação e Cultura (MEC), os centros de ciência tiveram uma atuação marcante na formação continuada de professores por meio de cursos de treinamento, especialização, aperfeiçoamento e seminários. Operavam também na edição e distribuição de publicações, na elaboração e tradução de projetos especiais e na assistência e orientação pedagógicas permanentes. Com perfil organizacional variado, os centros situavam-se, em alguns estados, em universidades ou institutos de pesquisa; em outros locais, eram vinculados ao sistema estadual de ensino.

No Brasil, a década de 1970 trouxe na sua bagagem o regime político militar instaurado em 1964, que vigoraria até a metade da década seguinte. $\mathrm{O}$ mundo vivia a crise do petróleo e as conseqüências das agressões ao ambiente, provocadas pelo acelerado desenvolvimento industrial de alguns países. A sociedade caracterizavase pela contestação dos padrões e valores estabelecidos e por desilusões e insatisfações com o sistema educacional. As questões mais efervescentes giravam em torno da consciência ecológica, o que exigiu um posicionamento proeminente das comunidades científica e educacional. O ensino de ciências incorporou então um novo elemento, fundamental para atender a esse cenário: a educação ambiental e suas implicações sociais. Os CECIs, apesar da falta de apoio financeiro e político que por várias vezes colocou em risco a sua sobrevivência, não deixaram de existir e nem permitiram a destruição do que vinha sendo feito para a formação continuada dos professores de ciências. Cabe ressaltar que esses centros, bem como a Sociedade Brasileira para o Progresso da Ciência (SBPC) e as sociedades científicas nas áreas de física, química e matemática, abriram espaço, nos seus foros de discussão sobre a educação científica, para movimentos sociais que contribuíram decisivamente para a transição democrática do país.

De modo geral a década de 1980 foi marcada pela recessão econômica, que afetou principalmente os países em desenvolvimento. Alguns de seus efeitos foram o desemprego, aumento dos índices de violência social e a piora das condições de atendimento nas áreas de educação e saúde. Surgiram as reações por parte dos movimentos sociais, que reivindicavam direitos políticos, econômicos, culturais e, notadamente, a construção da cidadania pela educação.

No Brasil, o grande acontecimento foi a passagem de um regime autoritário para um regime participativo, com eleições diretas para a Presidência da República. A construção de uma sociedade democrática tornou-se o objetivo central das atividades na área da educação, e o ensino de ciências continuava aglutinando as preocupações dos órgãos decisórios da educação científica no país. Em 1983 a Coordenação de Aperfeiçoamento de Pessoal de Nível Superior 
(CAPES) cria um novo projeto, que passa a constituir o Subprograma Educação para a Ciência (SPEC), vinculado ao Programa de Apoio ao Desenvolvimento Científico e Tecnológico (PADCT). O projeto apoiou a formação e a consolidação de grupos de pesquisas em ensino de ciências e matemática, a publicação de periódicos na área, bem como atividades de treinamento e formação de professores (Franco, Sztajn, 1999). Os centros de ciências, por sua vez, foram redimensionados e tiveram diversificadas as suas estratégias, para melhor se sintonizarem com as intervenções na área do ensino de ciências e atender ao necessário aprimoramento profissional dos docentes.

Nesse mesmo período surgem os primeiros museus de ciência e tecnologia com caráter dinâmico, buscando se projetar como instituições de comunicação, educação e difusão cultural voltadas para um público amplo e diversificado. No Rio de Janeiro são criados o Espaço Ciência Viva (independente) e o Museu de Astronomia e Ciências Afins (MAST), então vinculado ao Conselho Nacional de Desenvolvimento Científico e Tecnológico (CNPq) e hoje, ao Ministério de Ciência e Tecnologia (MCT); em São Paulo, o Centro de Divulgação Científica e Cultural (CDCC) da Universidade de São Paulo (USP/ São Carlos), a Estação Ciência (do CNPq; hoje, USP) e o Museu Dinâmico de Ciências de Campinas da Universidade de Campinas (Unicamp) e Prefeitura de Campinas; e na Bahia, o Museu de Ciência e Tecnologia da Universidade do Estado da Bahia (UNEB). O acontecimento é resultado de um processo que teve início na década de 1960 no contexto internacional, quando uma intensa discussão apontou uma mudança da prática e do papel social dos museus. No bojo desse movimento, os museus de ciência e tecnologia tiveram atuação preponderante. Seus propósitos iam além da preservação de artefatos marcantes para a história da ciência e da investigação sobre eles; concentravam-se em torno da difusão de princípios científicos e tecnológicos, a fim de induzir os jovens às carreiras pertinentes a essas áreas.

A assinalar ainda mais tal mudança surge, principalmente nos Estados Unidos, um tipo de museu de ciência de contorno multidisciplinar integrando ciência, tecnologia e arte e recorrendo amplamente às técnicas interativas de caráter experimental. São os denominados science centers, espaços que provocam, atraem, seduzem e motivam o visitante a entrar em contato com alguns fundamentos da ciência e da tecnologia por meio de experimentos do tipo 'faça você mesmo'.

No conjunto social urbano havia, entretanto, uma contradição: as pesquisas de opinião pública ao mesmo tempo que constatavam a existência de uma parcela da sociedade interessada em conhecer controversos assuntos científicos (energia nuclear, aditivos químicos, controle ambiental, engenharia genética etc.) para uma 
participação mais bem-informada, acusavam baixos níveis de compreensão sobre ciência e tecnologia, evidenciando que algo deveria ser feito para melhorar a situação, denominada 'analfabetismo científico' por alguns autores. Ocorreu, então, um encontro entre a necessidade de melhorar o nível de compreensão sobre ciência e tecnologia e os propósitos dos museus de ciência de contorno mais interativo. Estes espaços foram eleitos como fontes importantes de aprendizagem fora do âmbito escolar, que proporcionariam uma educação continuada em ciências após o término da educação formal. É importante lembrar que esses centros não são as únicas fontes não-formais de aquisição de informações científicas. Existem, entre outros, os programas de televisão e as matérias publicadas em jornais e revistas. A reunião dos distintos canais de divulgação científica passa a representar, para a sociedade, um caminho para melhorar seu entendimento sobre o universo científico, reforçando a ligação entre informação, entretenimento e aprendizagem.

As novas abordagens propostas para minimizar o analfabetismo científico e tecnológico são incorporadas pelos museus de ciência. Seu enfoque principal são os fenômenos e conceitos científicos. A comunicação entre os visitantes e a ciência é mediada por uma maior interatividade com aparatos que põem em relevo a ação do sujeito na aprendizagem. As equipes profissionais passam a considerar em seus projetos de exposições um conjunto de evidências oriundas de pesquisas sobre ensino-aprendizagem de ciências. A idéia do 'aprender fazendo', bastante difundida no ensino de ciências, encontra nos museus interativos um meio de divulgação.

Na década de 1990 novos museus foram criados no Brasil, dentre eles o Museu de Ciência e Tecnologia (da Pontifícia Universidade Católica do Rio Grande do Sul - PUC-RGS); o Espaço Ciência, em Recife, Pernambuco; o Espaço Museu da Vida, da Casa de Oswaldo Cruz/Fundação Oswaldo Cruz, no Rio de Janeiro; e o Espaço Museu do Universo, da Fundação Planetário, na mesma cidade. O campo da educação se vê cada vez mais fortalecido, inclusive com investimento de recursos públicos na área. A par disso, ou talvez por conseqüência, várias críticas são desenvolvidas no sentido de reavaliar os objetivos dos museus de ciência frente à realidade contemporânea. $\mathrm{O}$ amadurecimento das discussões sobre educação não-formal, principalmente sobre os museus de ciência brasileiros, é reflexo do panorama internacional do momento e do modo como essas instituições se moldaram, ao longo de sua história, a partir do diálogo entre ciência e sociedade, notadamente na especificidade de seu objeto. Detalharemos tal aspecto a seguir. 


\section{Museus de ciência: uma perspectiva de análise}

Quando se analisa detalhadamente o campo dos museus de ciência, percebe-se a presença permanente de uma questão: qual é o objeto específico dessas instituições?

Para essa discussão, Montpetit (1998) propõe três abordagens: a ontológica, a histórica e a epistemológica. $\mathrm{Na}$ abordagem ontológica, o 'eixo museológico' é o real - a natureza e suas causas - e tem por objeto a globalidade do universo. Nos museus que adotam tal orientação, o discurso científico está presente, porém de forma implícita, ou seja, não se torna um objeto em si. A ênfase recai na realidade - representada pelos minerais, animais e vegetais -, que deve ser compreendida por meio da ciência. Na abordagem histórica, o 'eixo museológico' é o discurso entendido como construção de uma narrativa coerente com a história da ciência e da técnica, com destaque para seus grandes momentos e personagens e tendo como mote uma coleção de artefatos. Dessa forma, "essa aproximação histórica liga o domínio da ciência e das técnicas à aventura humana dos temas conhecidos e mostra as influências que as ciências e suas aplicações tiveram sobre a vida em sociedade" (idem, ibidem, p. 176). Já a abordagem epistemológica está presente nos museus que focalizam a análise, a construção e o desenvolvimento do discurso científico em si. Nessas instituições o 'eixo museológico' que prevalece é o da ação. Demonstra-se, por meio de aparatos, instrumentos científicos e modelos, como o processo científico se constrói e funciona, ou como os fenômenos científicos acontecem.

Os museus de ciência, portanto, podem ser vistos por diversas óticas, correspondentes a concepções distintas da ciência e da técnica, mas também conforme a relação promovida com o seu público. Em outras palavras, as abordagens conferem a esses locais perfis distintos, que se refletem nas diferentes exposições, estas caracterizadas segundo a forma de negociação estabelecida com o visitante. Nas instituições que privilegiam a abordagem ontológica, as exposições estão centradas em coleções de relevância científica e apresentam de forma exaustiva numerosos espécimes. Suas origens remontam aos gabinetes de curiosidade, os museus se estabelecem motivados pelas interrogações relativas ao lugar do homem na natureza e constituem locais de pesquisa e difusão de conhecimento. Em geral têm um caráter enciclopedista, contando com a contribuição de diferentes áreas das ciências. Gould (1994, p. 9), ao se manifestar sobre o Muséum National d'Histoire Naturelle de Paris, observa: "os homens pensaram então poder reunir de todos os cantos do mundo todas as formas importantes de vida e guardálas sob um único teto para nosso encantamento, nossa glória e a celebração de nosso poder". Nesses lugares a aproximação com o visitante se faz pela apresentação de uma trama evolutiva que con- 
templa a cosmologia e o surgimento da vida e do homem. A relação com o público se constrói por duas formas: aos visitantes predominantemente leigos, que compõem o público geral, procuram mostrar os extratos do mundo natural, vegetal, mineral e animal; para o público de especialistas, oferece a oportunidade de elaborar e verificar, pela pesquisa, as teorias sobre a ordem da natureza e sua evolução. São os museus de história natural, e a eles podem ser agregados os parques, zoológicos e jardins botânicos.

O segundo tipo de abordagem molda as instituições que destacam artefatos relevantes da história da ciência e da técnica, interpretados freqüentemente a partir da história social. Museus que privilegiam tal abordagem situam-se nos campos da história, etnografia e antropologia. Em geral suas temáticas exploram o desenvolvimento das técnicas e das ciências nas diferentes culturas, o que demarca a passagem da sociedade tradicional para a industrial. Tratam das inovações que afetam o cotidiano da sociedade, tais como a invenção da máquina a vapor e da eletricidade. Três museus são considerados paradigmáticos dessa perspectiva histórica: o Conservatoire des Arts et Métier (Paris), o Science Museum (Londres) e o Deutsches Museum (Munique).

O Conservatoire des Arts et Métier (hoje Musée National de Téchnique de Paris) é considerado o pioneiro desse tipo de museu. Criado em 1794, reúne peças dos campos da agricultura, mecânica, física, química, energia e astronomia provenientes do século XVI ao XX (Hernández, 1998). Sobre ele, interessa destacar, além do aspecto cultural de preservação de testemunhos do passado, sua preocupação com os aspectos educativo e lúdico da exposição. $\mathrm{O}$ educativo se fazia presente na apresentação comentada de objetos e em demonstrações sobre o funcionamento de determinadas peças; o lúdico manifestava-se nas atividades dos especialistas colocando as máquinas em funcionamento, o que resultava em um verdadeiro espetáculo. Tais características, que permitem classificar o Conservatoire como um museu do 'saber fazer', seriam enfatizadas nos museus posteriores de ciência e técnica.

Cabe acrescentar que a $1^{\text {a }}$ Exposição Internacional teve forte influência na implementação desses museus paradigmáticos, que incorporaram muitas das características daquele evento, as quais continuam sendo observadas pela museografia atual. Dentre elas podemos destacar: no espaço, destinado ao atendimento de uma freqüência maciça, arquitetura e exposições formavam um todo a ser contemplado; o uso de publicações explicativas para orientação dos visitantes; a articulação de passado, presente e futuro; a preocupação com o aspecto visual do conjunto da exposição e com a adoção de diferentes recursos e meios técnicos para criar um ambiente agradável à visitação (idem, ibidem). 
A abordagem epistemológica dá forma aos museus de ciência centrados na experiência científica e originados de espaços destinados à pesquisa, como salas de anatomia, laboratórios de departamentos universitários, institutos e outros. Restritas a princípio aos especialistas, tais instituições têm como objeto central a própria ciência e sua forma de pensar e representar o mundo. Nesses museus procura-se comunicar ao visitante como o processo científico se constrói e funciona, introduzindo-o no trabalho científico e em seus métodos, permitindo-lhe observar, por meio de dispositivos concebidos para este fim, a ciência 'em ação' e, por vezes, até mesmo participar do experimento. Com a mesma abordagem, porém em uma versão popular, foram criados os science centers, inspirados em concepções que remontam ao início do século XX e procuram uma aproximação com o público a partir de preocupações marcadamente pedagógicas. De fato, já em 1903 o Deutsches Museum abriu suas portas assumindo essa dimensão, ao apresentar objetos que podiam ser manipulados pelos visitantes e oferecerlhes a possibilidade de usá-los e experimentá-los. Três décadas depois inaugurava-se o Palais de la Découverte, em Paris, com o propósito explícito de motivar os visitantes e instruí-los sobre os princípios da ciência e da técnica por meio da demonstração de fenômenos científicos e aparatos com dispositivos que, uma vez acionados, permitiam experimentar a ocorrência de tais fenômenos. Também na década de 1930, o Museum of Science and Industry abria suas portas em Chicago, dando destaque à forma lúdica na apresentação de seus conteúdos.

As mesmas características foram posteriormente assumidas pelas tendências museográficas consolidadas na década de 1960, com a abertura do Ontario Science Centre, em Toronto, e do Exploratorium, em São Francisco. Estes foram os primeiros representantes dos denominados science centers e identificaram-se mais como meios de comunicação de massa, usados como instrumentos de promoção da ciência e da técnica, consideradas elementos culturais. Acompanhando a tendência, a década de 1980 testemunhou a criação de novos espaços como a Cité des Sciences et de L'Industrie - La Villette, em Paris. A grande maioria desses empreendimentos caracterizou-se por ter seus aparatos reproduzidos em espaços similares por todo o mundo, efetivando uma verdadeira indústria de museus interativos de ciência (Beetlestone et alii, 1998).

Nesses tipos de museus, os visitantes têm a oportunidade de protagonizar ações/descobrimentos, ou seja, convertem-se em sujeitos ativos, uma vez que têm uma relação direta com os aparatos por meio da manipulação destes ou da observação de como os outros os manipulam.Assim, o público experimenta de forma direta, viva e lúdica o fato científico. 


\section{Museus de ciência: caminhos a percorrer}

No pós-guerra imediato distingue-se um momento caracterizado como a 'idade da ciência', não somente herdeira das conquistas fundamentais do século XIX mas também produtora de um espetáculo de inovação e desenvolvimento sem precedentes na história da ciência, em termos de volume e diversidade. Os últimos 20 anos do século $X X$, por sua vez, desenharam um movimento que conformou uma nova era, a 'idade da tecnologia' (Granger, 1994, p. 11). Especificamente com relação aos museus de ciência, as questões manifestadas na sociedade alteraram o papel dessas instituições, que passaram a ter como principal missão comunicar e socializar o conhecimento. Este novo modo de pensar está associado ao contexto globalizado do mundo, que recria novas formas de o sujeito se conceber como participante ativo de um grupo, com direito a consumir bens e informação. Em tal ambiente, a educação deve promover a formação de cidadãos capazes de interferir criticamente na realidade para transformá-la (Macedo, 2002, p.137).

Para Lins de Barros (2001), realidade e ciência tornaram-se absolutamente distantes da sociedade, que hoje sente mais o impacto de novas tecnologias como, por exemplo, a computacional, a robótica e a nanotecnologia. Nunca se guardou, processou e transmitiu tanta informação como atualmente, o que promete continuar se multiplicando. A natureza analisada pela física parece ser mais complexa do que se pensava há dez anos. Devido à capacidade de guardar, processar, interpretar e reunir informação e à imposição de limites teóricos, a ciência abandonou parcialmente seus propósitos iniciais e tornou-se mais pragmática. Não é mais a investigação pela verdade oculta que guia o esforço científico, mas algo prático, que permita o alcance de objetivos com maior eficiência. Dessa forma, a ciência encontrou na tecnologia um parceiro muito produtivo para juntos atuarem de forma global, promovendo uma mudança de escala em seus efeitos sobre a sociedade. Até os anos 1980, a física ocupava o lugar de paradigma para a descrição da natureza; hoje a biologia, em especial as biotecnologias, aproxima-se cada vez mais desta posição.

Ciência, tecnologia e inovação têm sido fatores essenciais no competitivo processo de desenvolvimento de diversas nações. Nos últimos anos, conceitos como integração, globalização e internalização permeiam uma série de mudanças sociais, nas quais a interface ciência/política/educação está profundamente implicada. Ciência e tecnologia estão presentes em um amplo espectro de setores da sociedade e relacionam-se com uma variedade de contextos, sejam estes pessoais (saúde, uso de medicamentos, entre outros) ou públicos (alimentos geneticamente modificados, camada de ozônio, energia nuclear etc.). Os cidadãos vivem crises e conflitos de 
diferentes naturezas que enfatizam mais e mais a necessidade de seu envolvimento na resolução de questões sociocientíficas.

Nesta época marcada pelo desenvolvimento científico e tecnológico, torna-se pertinente examinar como a educação formal e a não-formal podem ajudar as pessoas a entenderem tais avanços. $\mathrm{O}$ novo cenário encontra-se alicerçado na preocupação com a formação de cidadãos preparados para enfrentar os desafios emergentes no século XXI. É certo que a enorme quantidade de conhecimento científico produzido trouxe, e ainda traz, benefícios para o bem-estar e para a melhoria da vida das pessoas. Entretanto um certo desconforto se faz presente na sociedade em geral, especialmente no que se refere a algumas das conseqüências na aplicação desse conhecimento em áreas sobre as quais não há consenso entre os cientistas, como é o caso da clonagem, do clima global e dos alimentos transgênicos. Tais preocupações se acirram com o aumento da consciência de que, embora tenha produzido nos últimos três séculos boa parte das nossas certezas, a ciência revelou sua incapacidade de oferecer diagnóstico seguro para uma série de outros assuntos. Uma boa representação do cenário contemporâneo é a imagem do loop da montanha-russa, mencionada por Sevcenko (2001): desequilíbrio social, degradação do meio ambiente, insegurança e domínio da tecnologia.

Beck (op. cit.) argumenta que estamos em uma 'sociedade de risco'. E, como bem acrescenta Giddens (1997, p. 220), os riscos estão associados à 'fabricação de incerteza', ou seja, "muitas das incertezas com que nos defrontamos hoje foram criadas pelo próprio desenvolvimento do conhecimento humano". A aparente contradição - avanço científico e tecnológico e fabricação de incerteza - modifica o modo de produção do conhecimento científico até então vigente e coloca em cheque a confiança depositada no que Giddens (1991, p. 35) denominou 'sistemas especialistas', definidos como "sistemas de excelência técnica ou competência profissional que organizam grandes áreas dos ambientes material e social em que vivemos hoje". Em campos como a medicina e a agricultura, as decisões e ações dos sistemas especialistas, bem como os resultados de pesquisas são objetos de grande debate popular (Fensham, 1999). A futura relação entre especialistas, ciência e nãoespecialistas não pode mais estar baseada na forma tradicional de dependência nesses sistemas, mas no reconhecimento mútuo das contribuições que cada lado pode oferecer para que, juntos, tomem decisões que dizem respeito à sociedade em geral. Cazelli e Franco (op. cit., p. 10) assinalam que, nessa nova relação entre ciência e sociedade, a expressão "agir na urgência, decidir na incerteza", de Perrenoud, "torna-se uma imagem adequada para sintetizar processos decisórios em que cidadãos, políticos, gestores públicos ou empresários tomam decisões acerca de questões como a dos alimentos transgênicos e outros temas de grande impacto social". 
Quais são as implicações dessas mudanças para a educação e, em especial, para a educação em ciências? Que tipo de educação científica contribuirá para a tomada de decisão dos cidadãos? Em face da complexidade de relações que caracteriza esse cenário, é claro que a aquisição, por parte dos alunos, de um grande número de fatos, conceitos e teorias científicas não satisfaz mais as reais necessidades de formação das futuras gerações. A educação científica deve, entre outros aspectos, possibilitar que os estudantes obtenham algumas idéias de como as investigações científicas são conduzidas (Jenkins, 1999) e ganhem habilidade para tomada de decisões nas discussões sociocientíficas. No entanto esta não é uma questão trivial. Várias abordagens têm sido exploradas, cujas soluções envolvem instituições tanto de educação formal quanto não-formal (Young, Glanfield, 1998). A discussão sobre o papel da ciência na aquisição dessa habilidade específica é central para a educação que objetiva a democratização da sociedade, pois é cada vez mais importante que tais decisões não se limitem a um grupo de pessoas.

A antiga bandeira 'science for all' não deve ser um discurso vazio, mas propugnar de fato o acesso ao conhecimento científico pelos estudantes em geral, e não somente com o intuito de selecionar e preparar futuros cientistas (Fensham, op. cit.). Este preceito traz conseqüências para o currículo, o ensino e a aprendizagem de ciências, mas sobretudo impõe a necessidade de reavaliar o que é considerado básico em educação em ciências, de forma a ajudar jovens a pensar, entender o que é feito, resolver problemas, enfrentar situações novas, questionar o conhecimento difundido pela mídia e interagir conscientemente com o mundo ao seu redor. As abordagens desenvolvidas para a educação em ciências esteve centrada na propagação do mito otimista da ciência, por meio de um ensino que visava "mais a introjeção da confiança em sistemas especialistas do que no domínio efetivo da ciência e seus processos" (Cazelli, Franco, op. cit., p. 18).

\section{Museu de ciência: comunicação, educação e negociação}

Como os museus responderão às demandas do século XXI? Com certeza deverão definir mais claramente sua função social. Mas este desafio coloca outras questões. Que papel os museus terão na produção e distribuição do conhecimento? Que conhecimentos ou perspectivas devem priorizar? Como os objetos tradicionais desses espaços sobreviverão à imposição dos meios eletrônicos? Quais áreas profissionais deverão ser incorporadas às equipes de trabalho? No cerne de tal discussão estão, sem sombra de dúvida, a dimensão educacional e, mais recentemente, a comunicação, inerentes à relação entre o museu e seus muitos diversos públicos. E o desafio 
atual é a redefinição dos caminhos que levam ao uso efetivo dos museus e de suas coleções.

Conforme já mencionado neste artigo e sublinhado por Montpetit (op. cit.), no passado os visitantes se contentavam e conformavam em contemplar o que era exposto. Paulatinamente uma maior ênfase foi dada à participação dos visitantes nas exposições, a partir da introdução de outros recursos museográficos. A compreensão de uma nova regra do jogo levou à adoção de um comportamento exploratório dos temas expostos, por meio de aparatos interativos. A incorporação definitiva dessa nova regra obriga a considerar os limites e as dificuldades relacionadas com a oferta de experiências realmente significativas. Para lidar com esta realidade é importante observar, além dos aspectos educacionais, os processos de comunicação que estão sendo incorporados nos museus.

Segundo Hooper-Greenhill (1998, p. 11), "todo o processo de comunicação atua como um conjunto de mensagens intencionadas, que também pode ser entendido como um conjunto de mensagens não-intencionadas". A intencionalidade da comunicação, nos museus, aparece em suas exposições, suas atividades e em seus materiais de divulgação. Já as mensagens não-intencionais originam-se na relação que o público estabelece com o museu e são marcadas por uma dose de imprevisibilidade. O museu adquire, portanto, o papel de comunicador, uma vez que coloca em discussão a necessidade de estabelecer outras formas de negociação com o público que considerem esses aspectos. Em outras palavras, nos museus a comunicação ganha novos contornos a partir da expansão de seu papel educativo, reflexo das atuais demandas educacionais da sociedade. Nas práticas desenvolvidas nesses espaços, os visitantes exercem um papel essencial, pois são para eles que tais práticas se destinam. Apesar da aparente obviedade desta afirmação, ela revela toda a sua complexidade quando o tema da comunicação é abordado plenamente pelos museus. Isso porque o público dos museus não inclui somente os visitantes reais, mas também os possíveis visitantes e outros tipos de usuários dos produtos ali elaborados (professores, consultores etc.).

Um dos desafios impostos aos museus é o desenvolvimento de estratégias de comunicação que, ao mesmo tempo, mantenha o entusiasmo pela instituição para o visitante real e promova uma aproximação dos grupos tradicionalmente excluídos. Análises sobre esta questão podem oferecer subsídios para o aperfeiçoamento de processos de consulta, intercâmbio de opiniões e negociação, com os quais os museus trabalharão para redefinir futuramente sua função. A inclusão de profissionais de marketing nas equipes de trabalho pode trazer contribuições significativas e inovadoras. Esta nova forma de pensar os museus vem propondo soluções conciliatórias entre os métodos tradicionais de comunicação realizados por 
esses espaços (com características dos processos comunicacionais de massa) e outros que possibilitem o intercâmbio de idéias entre as partes envolvidas (o público e a equipe do museu).

Na elaboração das práticas sociais, as soluções buscam resgatar as necessidades dos visitantes, além de proporcionar oportunidades de compartilhamento e participação, seja por meio da manipulação dos aparatos ou por visitas guiadas. Em resumo, as formas de comunicação nos museus têm evoluído e passaram de um modelo simplificado - baseado na idéia emissor-receptor, de envio de uma mensagem linear a uma pessoa - para um modelo mais complexo constituído por elementos como a intenção por parte do emissor, o conteúdo da mensagem, a linguagem utilizada, as condições do visitante, os recursos audiovisuais e, principalmente, a possibilidade de estabelecer relações em um sentido até então não previsto: as do visitante com o museu.

O novo modelo revela dificuldades no que concerne à recepção da mensagem, que deverá ser modificada até que se alcance a sua compreensão: "quanto maior o processo de compartilhamento, maior a comunicação e provavelmente mais efetiva ela será" (idem, ibidem, p. 68). Impõe-se, assim, aos museus uma nova dinâmica na elaboração de exposição, que requer consciência do volume e da qualidade do trabalho a ser realizado antes de se iniciar o processo comunicativo. É essencial ter em mente que o processo de comunicação é compartilhado, e se as partes não participam ele não ocorre. Outro aspecto a ser considerado é a amplitude da função comunicadora dos museus, que se manifesta de múltiplas formas e afeta todas as atividades. Ao acatar a importância do visitante nos espaços museológicos, a comunicação procura desenvolver meios cada vez mais complexos que facilitem a apreensão das informações veiculadas nas exposições e colaborem na interpretação. Trata-se de desenvolver uma mediação facilitadora entre os públicos e o saber. A tendência, nomeada por alguns autores como 'museologia da idéia' (Davallon, 1992; Hernández, op. cit.; Montpetit, op. cit.), tem como concepção subjacente o estabelecimento de uma comunicação com o saber. A forma mais privilegiada de alcançar tal objetivo é a interatividade, possuidora de características eminentemente lúdicas, ou seja, ao mesmo tempo que informa, entretém.

A interatividade é considerada uma pedagogia não-diretiva e deve ser entendida como um conceito ampliado que oferece ao público a oportunidade de experimentar fenômenos e participar nos processos de demonstração ou na aquisição de informações, com o propósito de ampliar seus conhecimentos. Dessa maneira, a 'museologia da idéia' recorre a um conjunto de técnicas de comunicação (computadores, vídeos, painéis animados ou robotizados etc.) para tornar as práticas sociais mais atrativas, transmitindo informações aos visitantes e motivando-os. O público atual não se con- 
tenta em ler textos ou assistir audiovisuais; ele deseja e anseia participar de forma ativa em experiências nas quais supõe realizar determinadas atividades, tais como responder perguntas e iniciar seqüências de encontros interativos. Entretanto, devido às atuais características das sociedades contemporâneas, os museus deverão ultrapassar um obstáculo existente no conceito de interatividade: a ausência da dimensão social em sua concepção atual. Freqüentemente, o foco da interatividade concentra-se nas dimensões cognitiva e prática, um reflexo da visão excessivamente otimista da ciência e da técnica.

A exploração de temas científicos sob a perspectiva histórica, contemplando seus aspectos sociais e culturais, permite perceber a ciência como uma construção humana coletiva. Além disso, a articulação de diferentes pontos de vista permite o alargamento do entendimento da ciência, da tecnologia e das relações sociais. Os instrumentos científicos ajudam a introduzir a conexão entre ciência e técnica junto ao público visitante. A apresentação desses objetos de forma isolada inevitavelmente oferece um entendimento muito limitado do pensamento científico. Eles devem ser mostrados sob uma perspectiva interdisciplinar, aproximando a ciência do visitante. Com isso, o público pode vir a dar um significado aos instrumentos, caso esteja familiarizado em algum nível com o que é apresentado. Para enfrentar as demandas impostas no presente contexto, os museus de ciência devem redefinir sua função social, principalmente a negociação mais estreita com os seus públicos. Neste jogo, os aspectos educacionais e comunicacionais tornam-se estratégicos, notadamente pela ampliação do conceito de interatividade, pela incorporação da dimensão social e pelo aprofundamento dos estudos de formas comunicacionais mais efetivas.

\section{Considerações finais}

Vivemos hoje em um mundo de transformações regidas por uma ordem global que ninguém compreende plenamente, mas cujos efeitos se fazem sentir em várias dimensões da vida cotidiana dos indivíduos. Nesse cenário de rápidas alterações, ganham grande relevância os níveis de cultura e alfabetismo científico, reclamados para a inserção social. Tais questões constituem um fenômeno de abrangência internacional, e as tentativas de sua solução não têm prescindido do fortalecimento de instâncias formais e não-formais de educação e da conexão entre elas, bem como da valorização da aprendizagem ao longo da vida, em especial a científica. Como conseqüência, os espaços de educação não-formal em ciências vêm ganhando destaque na elaboração das políticas nacionais de ensino e divulgação. Suas ações de cunho educacional e as pesquisas neles desenvolvidas - ambas relativas à fundamentação e prática da edu- 
cação científica da sociedade e ao aprofundamento da cultura científica do cidadão - asseguram-lhe o status de referência sobre o tema. Fensham (op. cit.) salienta que o conhecimento dos adultos sobre os temas científicos mais atuais e relevantes não advém das experiências escolares, mas da interação com as diversas mídias e os museus de ciência.

Vários organismos internacionais, com destaque para a Organização para a Cooperação e o Desenvolvimento Econômico (OCDE), têm incluído a cultura científica como meta, princípio ou objetivo de políticas científicas e tecnológicas. Godin e Gingras (2000) ressaltam um outro aspecto, que está relativo à variedade de meios pelos quais os indivíduos poderiam ser aculturados à ciência. Há grupos que atribuem prioridade à escola e outros indicam as várias mídias como veículos privilegiados, por considerarem a divulgação o cerne desse processo. Alguns especialistas enfatizam o valor da cultura científica para o desenvolvimento social dos cidadãos, porque os capacita a entender a base científica da sociedade moderna de modo a desempenharem um papel ativo nos debates sociais, enquanto que outros a percebem como um pré-requisito para o desenvolvimento econômico e a inovação.

A despeito dos inúmeros entendimentos do termo 'cultura científica', existe algo comum a todos eles: a idéia de apropriação. Independentemente do que se considere, seja o desenvolvimento da ciência, a democratização dos debates em torno dela ou a luta contra a alienação em uma sociedade cada vez mais norteada pelo desenvolvimento científico, esta idéia está presente. Godin e Gingras (ibidem, p. 44) interpretam a cultura científica como a "expressão de todos os modos por meio dos quais indivíduos e sociedade se apropriam da ciência e da tecnologia". Sobre esta noção, importa destacar que contempla tanto a dimensão individual como a social da ciência.

As exigências contemporâneas referentes sobretudo ao alfabetismo científico salientam a necessidade de os cidadãos se relacionarem com temas e conhecimentos científicos. Do mesmo modo, devem ser capazes de tirar conclusões baseadas em evidências, nas quais basearão suas decisões sobre o mundo natural e as mudanças nele provocadas pela atividade humana (Fensham, op. cit.; OCDE, 2000). A educação em ciências deve, pois, entre outros fatores, incorporar estratégias que possibilitem tal postura. No caso específico da educação formal, Jenkins (op. cit.) assinala a relevância da reestruturação dos currículos de forma a promover o entendimento dos estudantes sobre 'risco' e sua avaliação crítica. Já na educação não-formal, especialmente nos museus de ciência, o tema está presente na principal estratégia de comunicação com o público: a interatividade. Como sublinhado anteriormente, a incorporação de aspectos históricos e sociais aos fenômenos científicos torna-se imprescindível no atual contexto, em que se requer uma nova rela- 
ção com a ciência, não mais baseada no conhecimento de um grande número de fatos e nomes descontextualizados, mas na interface do conhecimento científico com sua aplicação e suas conseqüências.

O somatório de todos esses pontos, aliado à ampliação da demanda por padrões mais elevados de cultura e de alfabetismo científico têm levado muitos autores a insistir em que a promoção da cultura em geral, e do alfabetismo científico em particular, seja desenvolvida por uma rede de instâncias culturais (Falk, Dierking, 2000; Bourdieu, 1969), na qual os museus ocupem lugar de destaque. Ao longo dos anos intensificam-se pesquisa e práticas educacionais e comunicacionais relacionadas às exposições e/ou atividades em museus, configurando cada vez mais um campo específico de produção de conhecimento. Estudos e estratégias são empregados para disponibilizar aos visitantes conhecimento científico de qualidade e de forma acessível. O desenvolvimento de novas audiências vem sendo considerado uma importante estratégia cultural para os museus e estimula uma reflexão permanente sobre o melhor meio de promover acesso físico e intelectual a essas instituições por camadas sempre mais amplas da sociedade. Torna-se, então, importante saber como os indivíduos se apropriam dos temas veiculados pelos museus e como isso pode implicar mudanças de atitudes, valores, condutas etc.

Para que os museus, particularmente os de ciência, possam estabelecer um vínculo autêntico com seu público real e potencial é preciso que ofereçam experiências valiosas. Desse modo, não só se promove o aumento do número de pessoas a interagir nesses locais como amplia-se o seu papel social. Um público mais culto cientificamente estará em melhor posição para discutir, acompanhar e reivindicar políticas públicas referentes a questões atuais e controversas da ciência. Por conta disso, os programas de comunicação levados a cabo nos museus de ciência devem explorar conceitos e técnicas em que os aspectos sociais e culturais desse conhecimento estejam incorporados. Sob tal orientação, essas instituições adquirirão a função de mediadores entre a sociedade e os organismos decisórios. Faz-se necessário, então, aumentar o índice de alfabetismo científico da sociedade, por meio de políticas públicas mais amplas e com estratégias de curto, médio e longo prazos. Nelas estariam compreendidos o desenvolvimento e a manutenção dos programas a cargo dos espaços de divulgação científica, visando satisfazer as necessidades de aprendizagem em ciência e tecnologia durante a vida dos cidadãos. 


\section{REFERÊNCIAS BIBLIOGRÁFICAS}

Beck, U.

1997

Beetlestone, J. G. et alii.

1998

Bourdieu, P. 1969

Cazelli, S., Franco, C. 2001

Davallon, J. 1992

Falk, J. H., Dierking, L. D. 2000

Fensham, P. 1999

Franco, C., Sztajn, P. 1999

Giddens, A. 1997

Giddens, A. 1991

Godin, B., Gingras, Y. 2000

Gould, S. J. 1994

Granger, G-G. 1994

Heizer, A. 2002

Hernández, F. H. 1998

Hooper-Greenhill, E. 1998

Jenkins, E. W. 1999

Krasilchick, $M$. 1987

Kuhlmann Júnior, $M$. 2001
A reinvenção da política: rumo a uma teoria da modernização reflexiva. In: U. Beck et alii (org.). Modernização reflexiva: política, tradição e estética no ordem social moderna. São Paulo, Editora da UNESP, p. 11-71.

The science center movement: contexts, practice, next challenges. Public Understanding of Science, n. 7, p. 5-26.

L'amour de l'art: les musées d'art européens et leur public. Paris, Les Éditions de Minuit.

Alfabetismo científico: novos desafios no contexto da globalização. Disponível na internet em www.coltec.ufmg.br/ ensaio/portugues/indice/ v03n2/htmp03n2.htm.

Le musée est-il vraiment un média?

Publics et Musées, v. 2, p. 99-124.

Learning from museums: visitor experiences and the making of meaning.

Walnut Creek CA, Altamira Press.

School science and public understanding of science.

International Journal of Science Education, v. 21, n. 7, p. 755-63.

Educação em ciências e matemática: identidade e implicações para políticas de formação continuada de professores. In: A. F. B. Moreira (org.). Currículo: políticas e práticas. Campinas, Papirus, p. 97-114.

Risco, confiança, reflexividade. In: U. Beck et alii (orgs.). Modernização reflexiva: política, tradição e estética no ordem social moderna.

São Paulo, Editora da UNESP, p. 219-34.

As conseqüencias da modernidade.

São Paulo, Editora da UNESP.

What is scientific and technological culture and how is it measured? Public Understanding of Science, v. 9, n. 1, p. 43-58.

Préface. In: D. Bezombes (org.). La grande galerie du muséum national d'histoire naturelle. Paris, Éditions du Moniteur.

A ciência e as ciências.

São Paulo, Editora da UNESP.

Algumas reflexões sobre a inclusão da temática das exposições universais nos programas escolares. In: Museu da Vida, MAST (org.). O formal e o não-formal na dimensão educativa do museu. Rio de Janeiro, Museu da Vida/MAST, p. 32-5.

El museo como espacio de comunicación.

Madri, Ediciones Trea.

Los museos y sus visitantes.

Madri, Ediciones Trea.

School science, citizenship and the public understanding of science. International Journal of Science Education, v. 21, n. 7, p. 703-10.

O professor e o currículo das ciências.

São Paulo, EPU/EDUSP.

As grandes festas didáticas: a educação brasileira e as exposições internacionais (1862-1922). Bragança, Editora da Universidade São Francisco. 
Lins de Barros, $\mathrm{H}$. 2001

Lopes, M. M. 1997

Lopes, M. M. 1996

Lopes, M. M. 1992

Macedo, E. 2002

Montpetit, R. 1998

Neves, M. S. 2001

Organisation for Economic Co-operation and Development (OCDE). 2000

Sevcenko, N. 2001

Valente, M. E. 1995

Young, M., Glanfield, K. 1998
The role of museum of science in the technological age. Museologia, v. 1, p. 67-84.

O Brasil descobre a pesquisa científica: os museus e as ciências naturais no século XIX. São Paulo, Hucitec.

Le rôle des musées, de la science et du public au Brésil.

In: R. Waast (org.). Les sciences hors d'occident au XXe siécle. Paris, ORSTOM Éditions, p. 261-74.

A favor da desescolarização dos museus.

Educação e Sociedade, n. 40, p. 443-55.

Currículo e competência. In: A. C. Lopes, E. Macedo (orgs.).

Disciplinas e integração curricular: histórias e políticas. Rio de Janeiro, DPA Editora, p. 115-43.

Du science center à l'interprétation sociale des sciences et techniques. In: B. Schiele, E. H. Koster (org.). La révolution de la muséologie des sciences. Lyon, Presses Universitaires de Lyon/Éditions Multimondes, p. 175-86.

Uma arena pacífica. Em MAST (org.). Imagens do progresso: os instrumentos científicos e as grandes exposições. Rio de Janeiro, MAST, p. 2-8.

Measuring students knowledge and skills: the Pisa 2000 assessment of reading, mathematical and scientific literacy. Paris, OECD.

A corrida para o século XXI: no loop da montanha-russa. São Paulo, Companhia das Letras. (Virando séculos, 7)

Educação em museu: o público de hoje no museu de ontem. Dissertação de mestrado, Pontifícia Universidade Católica do Rio de Janeiro (PUC-Rio), Rio de Janeiro.

'Science in post-compulsory education: towards a framework for a curriculum of the future'. Studies in Science Education, v. 32, p. 1-20.

Recebido para publicação em outubro de 2002.

Aprovado para publicação janeiro de 2003. 